\title{
Microbiological and Physicochemical Quality of Enzymatically Peeled Persimmon Fruit for Fresh-cut Slices
}

\author{
Yukari Murakami \\ Faculty of Biology-Oriented Science and Technology, Kinki University, 930 \\ Nishimitani, Kinokawa, Wakayama, 649-6493 Japan \\ Yoshihiko Ozaki \\ National Institute of Fruit Tree Science, National Agriculture and Food \\ Research Organization, 2-1 Fujimoto, Tsukuba, Ibaraki, 305-8605 Japan
}

Hidemi Izumi ${ }^{1}$

Faculty of Biology-Oriented Science and Technology, Kinki University, 930
Nishimitani, Kinokawa, Wakayama, 649-6493 Japan

Additional index words. peeling method, pectolytic enzyme, fresh-cut fruits, microflora, microbial safety

\begin{abstract}
Enzymatic peeling of 'Fuyu' and 'Tone-wase' persimmon fruit was conducted for production of fresh-cut slices, and the microbiological and physicochemical quality of enzyme-peeled fresh-cut slices was compared with that of slices manually peeled with a knife. The enzymatic peeling process involved a porous treatment of the peel, heating at $100{ }^{\circ} \mathrm{C}$ for $45 \mathrm{~s}$, infusion with $3 \%$ protopectinase at $37^{\circ} \mathrm{C}$ for $3 \mathrm{~h}$, and rinsing under running tap water. Initially, the peel of 'Fuyu' persimmon fruit had microbial counts ranging from 3.9 to $4.2 \mathrm{log} \mathrm{cfu} \cdot \mathrm{g}^{-1}$ and a diverse microflora. The heating treatment before the enzymatic peeling process reduced the microbial counts in both the peel and flesh of all fruits to levels below the lower limit of detection. After the enzyme infusion followed by gentle rinsing with tap water, microbial counts of enzyme-peeled fruit were close to or below the level of detection. When microbial contamination of enzyme-peeled and knifepeeled 'Fuyu' and 'Tone-wase' persimmon slices was compared, the bacterial counts and diversity of bacterial and fungal flora were less in enzyme-peeled slices than in knifepeeled slices. With 'Tone-wase' slices, the color index, $\mathrm{pH}$, and texture were unaffected by enzymatic peeling, except for surface lightness, which was lower in enzyme-peeled slices than in knife-peeled slices. These results indicate that enzymatic peeling could be an alternative to knife-peeling of 'Tone-wase' persimmon fruit for fresh-cut production from the point of microbiological and physicochemical quality.
\end{abstract}

Peeling is a necessary process for the production of fresh-cut products. Chemical or mechanical peeling is the most common method for peeling of fruits and vegetables. However, these methods often lead to potential loss and damage of flesh and sometimes cause a waste disposal problem by the use of lye peeling. Alternative methods such as steam peeling (Garcia and Barrett, 2006) and abrasion peeling (Emadi et al., 2008) have been examined but there are still some limitations with waste of edible portions and quality losses. Thus, an enzyme-peeling method was developed to prevent these problems. Bruemmer et al. (1978) reported a method to remove the peel of grapefruit by placing scored samples in an enzymatic solution under vacuum. Since

Received for publication 28 Nov. 2011. Accepted for publication 17 Jan. 2012.

This research was part of the Program for Fostering Regional Innovation (City Area Type) sponsored by the Ministry of Education, Culture, Sports, Science, and Technology of Japan.

${ }^{1}$ To whom reprint requests should be addressed; e-mail izumi@waka.kindai.ac.jp. then, many studies for enzyme-peeling of citrus fruit have been conducted to investigate the optimum conditions of enzyme concentration, temperature, $\mathrm{pH}$, and time for achieving an efficient peeling process (Prakash et al., 2001; Pretel et al., 1997, 2007; Rouhana and Mannheim, 1994; Soffer and Mannheim, 1994). Physiological, physicochemical, and microbial quality of enzyme-peeled fruit segments was also determined with grapefruit (Pao et al., 1996), oranges (Pao et al., 1996; Pinnavaia et al., 2006), and mandarin (Liu et al., 2004). When sensory evaluation by color, odor, sliminess, firmness, appearance, and overall acceptability were compared between enzyme-peeled and hand-peeled mandarin segments, the panelists preferred enzyme-peeled segments mostly because of its clean, fresh, and appealing appearance (Liu et al., 2004). In addition to the research on citrus fruit, the enzymatic peeling treatment has been expanded for other fruits and vegetables such as mangoes (Sakho et al., 1998), apricots, nectarines, peaches (Toker and Bayindirlt, 2003), potatoes, carrots, Swedish turnips, and onions (Suutarinen et al., 2003).
With the enzymatic peeling technology in Japan, Ozaki et al. (2004) developed an enzymatic peeling method for Japanese persimmon fruits. The process includes hot water dipping, protopectinase infusion, and gentle rinsing with running tap water. However, they did not report the microbial contamination of persimmon fruit during the enzymatic peeling process and after the production of fresh-cut slices. The risk of microbial contamination of fresh-cut fruits should be controlled, because fresh and fresh-cut fruits can be the source for foodborne pathogens (Beuchat, 1996; Heaton and Jones, 2008). In the present study, we determined the microflora of 'Fuyu' and 'Tone-wase' persimmon fruit during the enzymatic peeling process and compared the microflora of enzymatically peeled fresh-cut slices with that of manually peeled fresh-cut slices using a knife. We also compared the difference in the microbial and physicochemical quality between enzyme-peeled 'Fuyu' and 'Tone-wase' persimmon slices to understand which cultivar is better for enzymatically peeled persimmons for fresh-cut slices.

\section{Materials and Methods}

Fruit materials. Sixty fruits each of 'Fuyu' and 'Tone-wase' persimmons (Diospyros kaki Thunb.) were obtained from a commercial grower in Wakayama Prefecture, Japan, in Dec. 2009 and Oct. 2010, respectively. Because 'Tone-wase' fruit are astringent persimmons, the harvested fruit were treated to remove astringency in a closed chamber with a $95 \% \mathrm{CO}_{2}$ atmosphere for $18 \mathrm{~h}$ at $25^{\circ} \mathrm{C}$. Fruit were transported from the persimmon orchard to the laboratory at Kinki University and stored at $20^{\circ} \mathrm{C}$ for 1 to $6 \mathrm{~d}$ before processing. Fruit samples were divided into two lots, one for enzyme-peeling and the other for knifepeeling treatments.

Processing. Calyces of fruits were removed with a sterilized knife, and then enzymatic peeling was performed according to a method of Ozaki et al. (2004) as follows: porous treatment of peel with a needlepoint holder allowing the penetration of enzymatic solution under the peel, heating treatment by submerging the fruit in a hot water bath at $100{ }^{\circ} \mathrm{C}$ for $45 \mathrm{~s}$ to inactivate the substances in the peel that inhibit the pectolytic enzyme, cooling treatment in tap water for $1 \mathrm{~min}$, infusion by dipping in $3 \%$ protopectinase (Pectinase-IGA; IGA Bio Research Ltd., Osaka, Japan) produced by Trichosporon penicillatum SNO-3 (Sakai, 1988) at $37{ }^{\circ} \mathrm{C}$ for $3 \mathrm{~h}$, and rinsing under running tap water for $1 \mathrm{~min}$ to remove the peel and any residual enzyme. As the control, fruit samples from another lot were peeled manually with a sharp stainless knife and then rinsed with running tap water. Our preliminary study revealed that microbial and physicochemical quality of the control slices was similar to that of knife-peeled slices with heating treatment at $100{ }^{\circ} \mathrm{C}$ for $45 \mathrm{~s}$. Thus, in this study, the knife peeling without heating treatment was used as the control to evaluate 
whether the enzymatic peeling is an alternative to the conventional knife peeling. Each peeling treatment using three fruits was replicated three times. The enzyme-peeled and knife-peeled fruit were sliced radially into four sections using a sterilized knife.

Microbial counts and identification. Microbial analyses of the samples from peel, flesh, and slices of three persimmon fruits were replicated three times. A fruit sample taken before peeling was aseptically separated into the stem end part of the peel, the equator part of the peel, and flesh using sterile scalpels. The portions of the flesh that came into contact with the scalpels were removed to avoid transfer of microorganisms from the surface peel to the flesh. Each sample was assessed for counts of mesophilic aerobic bacteria, coliform groups, and fungi as previously described (Izumi, 1999). A 10-g sample of peel, flesh, and slices was macerated in $90 \mathrm{~mL}$ of sterile saline solution in a sterile stomacher bag using an Elmex stomacher (Promedia SH-001; ELMEX, Tokyo, Japan) for $4 \mathrm{~min}$ at room temperature. The serial dilutions from each sample were made in sterile saline solution and then poured into duplicate plates containing either standard method agar (SMA; Nissui Pharmaceutical, Tokyo, Japan) and incubated at $37{ }^{\circ} \mathrm{C}$ for $48 \mathrm{~h}$ for enumeration of mesophiles or desoxycholate agar (Nissui Pharmaceutical) and incubated at $37^{\circ} \mathrm{C}$ for $24 \mathrm{~h}$ for enumeration of coliforms and into triplicate plates of potato dextrose agar (PDA; Nissui Pharmaceutical) with $100 \mathrm{ppm}$ of chloramphenicol and incubated at $26^{\circ} \mathrm{C}$ for $72 \mathrm{~h}$ for enumeration of fungi. Microbiological plate count was expressed as log colony-forming units per gram of peel, flesh, and slices.

For isolation of bacteria and fungi, the diluent of each sample was plated onto the surface of solidified SMA and PDA, respectively. Incubation conditions were same as the plates for enumeration. Twenty-five bacterial and 22 fungal ( 11 mold and 11 yeast) isolates and 26 bacterial and 45 fungal ( 34 mold and 11 yeast) isolates were selected from differentappearing types of colonies on petri plates from 'Fuyu' and 'Tone-wase' persimmons, respectively, based on stereoscopic observation. The MicroSeq microbial identification system (Applied Biosystems, Foster City, CA) was used for identification of bacteria and fungi. The sequencing data were analyzed using Analysis Software (MicroSeq analysis software Version 2.0, MicroSeq. 16S rDNA sequence databases Version 2.2 for bacteria, and MicroSeq. D2 LSU rDNA sequence databases Version 2.0 for fungi) as previously described (Poubol and Izumi, 2005). A cutoff of the lowest distance score from the sequence in the database was chosen for species identification.

Quality evaluation. Three replicated samples from enzyme-peeled and knife-peeled slices prepared from three persimmon fruits were evaluated for physicochemical quality as previously described (Poubol and Izumi, 2005). Surface color of the peeled side of three slices per replication was measured with a Handy Colorimeter (Model NR-3000; Nippon Denshoku, Tokyo, Japan). The L*, a*, and $b^{*}$ readings were recorded and the results were expressed as the $\mathrm{L}^{*}$ value (lightness) and chroma $C^{*}=\left(a^{* 2}+b^{* 2}\right)^{0.5}$ value. Surface $\mathrm{pH}$ of three slices was determined with a compact pH meter (Model B-113; Horiba, Tokyo, Japan). Texture of the three slices was measured by the force required to shear the slice with a cutter blade using an EZ test texture analyzer (Model AR-228; Shimadzu, Kyoto, Japan) and was expressed as a maximum shear force $(\mathrm{N})$.

Statistical analysis. Statistically significant differences $(P \leq 0.05)$ between enzymepeeled and knife-peeled flesh-cut slices were determined for microbial and physicochemical quality data based on an analysis of variance using the SAS system, Release 6.12 (SAS
Institute, Cary, NC). The mean values were compared using the Tukey's honestly significant difference method.

\section{Results and Discussion}

Microflora in 'Fuyu' persimmons during the enzymatic peeling process. Microflora in 'Fuyu' and 'Tone-wase' persimmon fruit were similar during the enzymatic peeling process, so only the results of 'Fuyu' persimmons are presented. Before processing, the stem end part of the peel had higher counts of $3.9 \mathrm{log} \mathrm{cfu} \cdot \mathrm{g}^{-1}$ for mesophiles and $4.2 \mathrm{log}$ $\mathrm{cfu} \cdot \mathrm{g}^{-1}$ for fungi, and the equator part of the peel had lower counts of mesophiles (less than $\left.2.4 \log \mathrm{cfu} \cdot \mathrm{g}^{-1}\right)$ and fungi $(3.1 \mathrm{log}$ $\mathrm{cfu}^{-\mathrm{g}^{-1}}$ ) (Fig. 1). The flesh showed the counts of $2.6 \mathrm{log} \mathrm{cfu} \cdot \mathrm{g}^{-1}$ for mesophiles and below the limit of detection $\left(3.0 \mathrm{log} \mathrm{cfu} \cdot \mathrm{g}^{-1}\right)$ for fungi. Counts of coliforms in the peel and flesh were below the limit of detection (2.4 $\log \mathrm{cfu} \cdot \mathrm{g}^{-1}$ ). The diversity of mold flora (four species belonging to four genera) and yeast flora (three species belonging to three genera) was comparatively less than that of bacterial flora (seven species belonging to five genera) (data not shown). The bacterial flora was comprised of Gram-positive bacteria such as the genera Bacillus and Curtobacterium belonging to soilborne organisms and Gram-negative bacteria such as the genera Pantoea and Pseudomonas belonging to phytopathogenic organisms. The isolated fungi were Aureobasidium, Fusarium, and Pestalotia in molds and Cryptococcus, Pseudozyma, and Sporidiobolus in yeasts, which are organisms living in a plant-soil environment. The flesh contained only one bacterial genus, Curtobacterium, and two mold genera, Aureobasidium and Pestalotia. This result was confirmed in our previous reports on 'Fuyu' persimmon fruit in the production field (Izumi et al., 2008a) and fruit-packing shed (Izumi et al., 2008b).
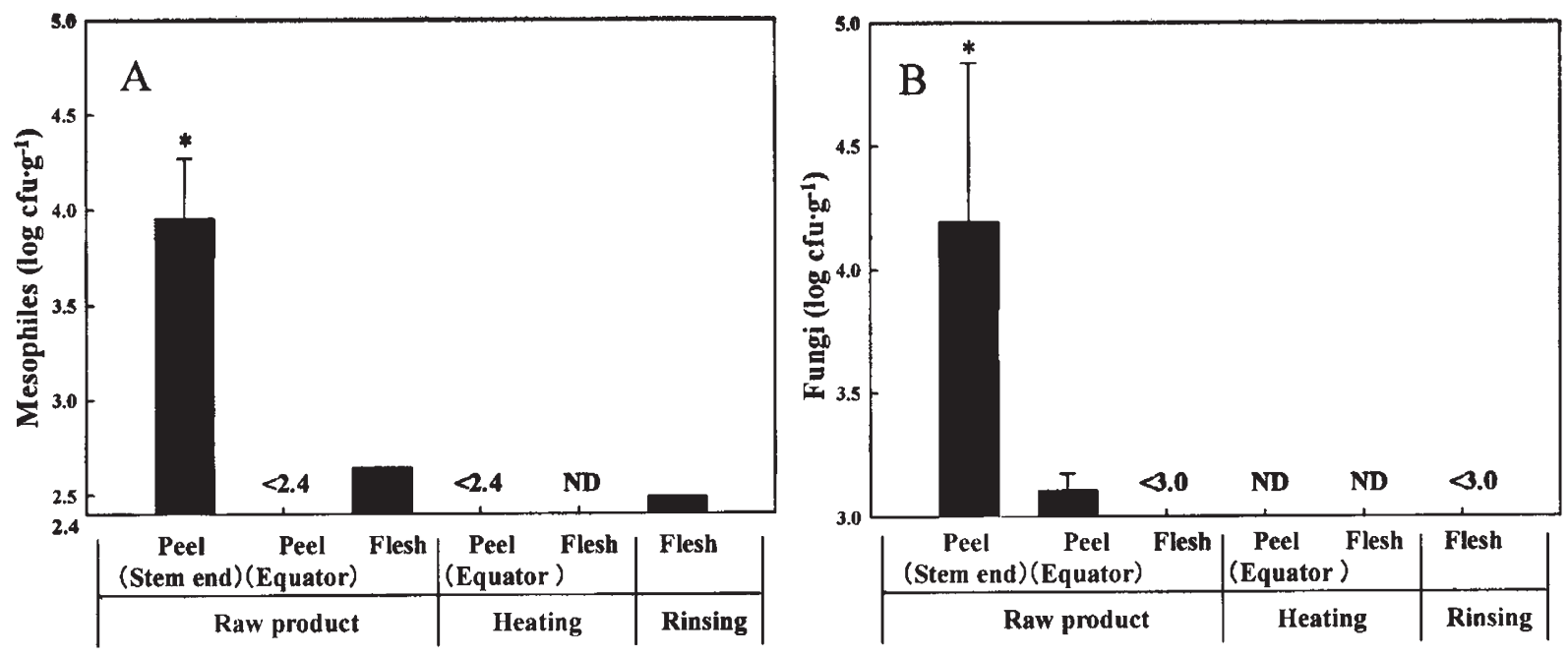

Fig. 1. Counts of mesophiles (A) and fungi (B) of 'Fuyu' persimmon fruit during the enzymatic peeling process. ND (not detectable) means no colonies detected on a plate of the original culture. Less than 2.4 or less than 3.0 means below the level of detection (fewer than 30 bacterial colonies or 10 fungal colonies on a plate of the original culture, respectively). Vertical lines represent SE. *Significant at $P \leq 0.05$ between the paired stem end part of the peel and equator part of the peel in raw product. 
During the enzymatic peeling process, after the fruit were submerged in hot water at $100{ }^{\circ} \mathrm{C}$, the microbial counts of the peel and flesh were reduced to levels below the limit of detection for mesophiles and at nondetectable levels for fungi (Fig. 1). After the subsequent pectinase infusion followed by gentle rinsing with tap water, microbial counts of flesh were close to or below $2.4 \log \mathrm{cfu} \cdot \mathrm{g}^{-1}$ for mesophiles and $3.0 \mathrm{log} \mathrm{cfu} \cdot \mathrm{g}^{-1}$ for fungi. With citrus fruit, counts of bacteria and fungi in enzyme-peeled oranges or grapefruit ranged from less than 1.0 to $2.3 \log \mathrm{cfu} \cdot \mathrm{g}^{-1}$ (Pao et al., 1996; Pinnavaia et al., 2006). Pinnavaia et al. (2007) reported that enzyme infusion followed by a citric acid dip of oranges reduced the microbial counts of fresh-cut slices to levels below $1.0 \mathrm{log} \mathrm{cfu} \cdot \mathrm{g}^{-1}$ and maintained the low counts throughout storage at $5{ }^{\circ} \mathrm{C}$ for $21 \mathrm{~d}$. With the enzymatic peeling process of persimmons in this study, the heating treatment used to inactivate the substances in the peel that inhibit the pectolytic enzyme successfully contributed to reduction of microbial counts in the peel and flesh of persimmons. Treatment with hot water at $76-85{ }^{\circ} \mathrm{C}$ for 1.5-6 min has been shown to effectively reduce microorganisms on cantaloupes (Fan et al., 2008; Solomon et al., 2006). The heating treatment at $100{ }^{\circ} \mathrm{C}$ for $45 \mathrm{~s}$ during the enzymatic peeling process served as hot water pasteurization.

Microbiological and physicochemical quality of enzymatically and manually peeled fresh-cut 'Fuyu' and 'Tone-wase' persimmon slices. When bacterial contamination of freshcut fruit slices that had been either enzymepeeled or knife-peeled was compared, counts of mesophiles were $1 \mathrm{log}$ and greater than 0.3 log higher in knife-peeled slices than in enzyme-peeled slices in 'Fuyu' and 'Tone-wase' persimmons, respectively (Fig. 2). Consequently, the bacterial counts in enzyme-peeled slices were similar between 'Fuyu' and 'Tone- wase' persimmons. Counts of coliforms of enzyme-peeled and knife-peeled slices were below the level of detection in both cultivars (data not shown). Fungus counts of enzymepeeled and knife-peeled slices were below the level of detection with 'Fuyu' persimmons, whereas fungi were not detected in enzyme-peeled 'Tone-wase' persimmon slices and below the level of detection in knifepeeled slices.

The diversity of bacterial flora was less in the enzyme-peeled slices (three species belonging to three genera in 'Fuyu' and four species belonging to four genera in 'Tonewase') than in the knife-peeled slices (six species belonging to six genera in 'Fuyu' and seven species belonging to five genera in 'Tone-wase') (Table 1). Bacteria isolated from slices were different between 'Fuyu' and 'Tone-wase' persimmons. Most of these bacteria are phytopathogenic and/or soilborne organisms such as the genera Klebsiella,
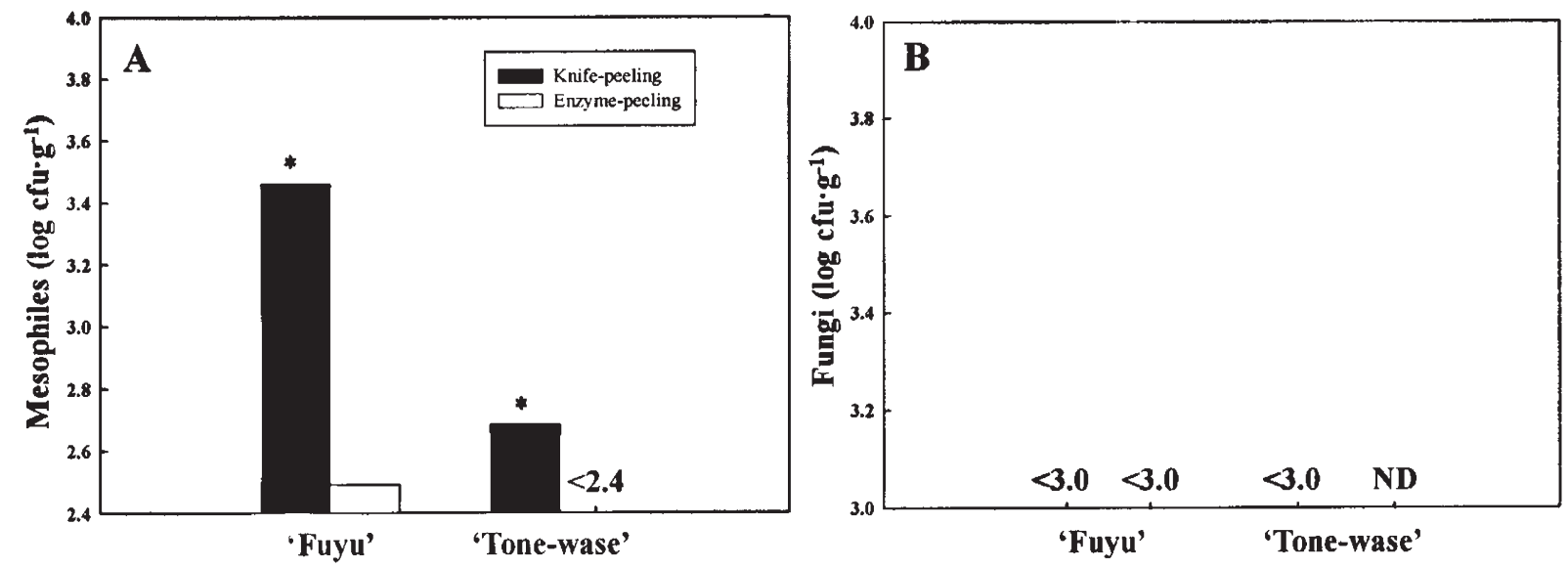

Fig. 2. Counts of mesophiles (A) and fungi (B) of knife-peeled and enzyme-peeled fresh-cut 'Fuyu' and 'Tone-wase' persimmon slices. ND (not detectable) means no colonies detected on a plate of the original culture. Less than 2.4 or less than 3.0 means below the level of detection (fewer than 30 bacterial colonies or 10 fungal colonies on a plate of the original culture, respectively). *Significant at $P \leq 0.05$ between paired knife-peeling and enzyme-peeling treatments.

Table 1. Bacteria and fungi isolated from knife-peeled and enzyme-peeled fresh-cut 'Fuyu' and 'Tone-wase' persimmon slices.

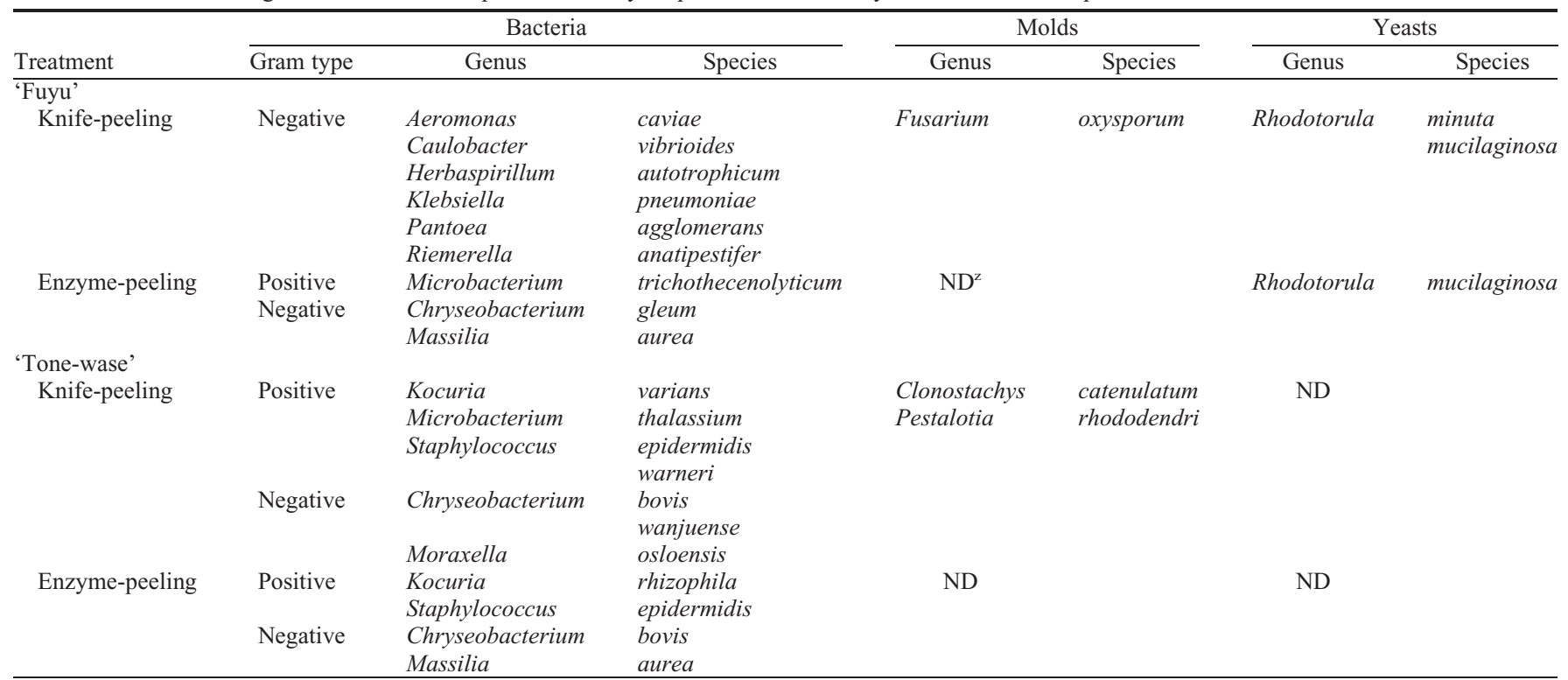


Table 2. Color indexes, pH, and texture of knife-peeled and enzyme-peeled fresh-cut 'Fuyu' and 'Tonewase' persimmon slices.

\begin{tabular}{|c|c|c|c|c|c|}
\hline \multirow[b]{2}{*}{ Quality attributes } & \multicolumn{3}{|c|}{ Fuyu } & \multicolumn{2}{|c|}{ Tone-wase } \\
\hline & Knife-peeling & Enzyme-peeling & & Knife-peeling & Enzyme-peeling \\
\hline L*value & $63.7 \pm 2.3^{z}$ & $51.1 \pm 1.3$ & $* \mathrm{y}$ & $69.4 \pm 1.1$ & $53.0 \pm 0.1$ \\
\hline $\mathrm{C}^{*}$ value & $58.4 \pm 2.0$ & $44.6 \pm 2.5$ & $*$ & $43.8 \pm 0.9$ & $41.3 \pm 0.5$ \\
\hline $\mathrm{pH}$ & $5.5 \pm 0.6$ & $4.6 \pm 0.0$ & $*$ & $5.5 \pm 0.0$ & $5.6 \pm 0.1$ \\
\hline Texture $(\mathrm{N})$ & $4.5 \pm 0.6$ & $5.0 \pm 0.8$ & & $7.7 \pm 08$ & $6.1 \pm 0.5$ \\
\hline
\end{tabular}

${ }^{\mathrm{z}}$ Mean \pm SE values.

y*Significant at $P \leq 0.05$ between paired knife-peeling and enzyme-peeling treatments.

Pantoea, Kocuria, and Chryseobacterium. Because potential sources of microbial contamination for persimmon fruit during growing and harvesting are from soil, agricultural water, pesticide solution, and packing-shed equipment (Izumi et al., 2008a, 2008b), the difference in field and packing-shed environments of 'Fuyu' and 'Tone-wase' persimmons may explain the differences in bacteria detected between the two cultivars of persimmons. The mold genera Clonostachys and Pestalotia were found only in the knife-peeled slices in 'Fuyu' and 'Tone-wase' persimmons. 'Fuyu' persimmon slices contained only the yeast genus Rhodotorula, whereas yeasts were not detected in any of 'Tone-wase' slices. The isolated fungi were organisms living in a plant-soil environment. Microbial contamination was much less in enzyme-peeled slices than in knife-peeled slices, probably as a result of the heating treatment in the enzymatic peeling process and the possibility of microbial transfer from the persimmon peel to flesh during peel removal and slicing the flesh with a knife. Because transfer of Salmonella from the rinds of cantaloupes to the fresh-cut tissues during cutting practices with utensils was reported (Ukuku and Sapers, 2001), the enzymatic peeling would be likely to assure microbiological safety of fresh-cut persimmons.

In terms of peeled surface color, $\mathrm{L}^{*}$ values on 'Fuyu' and 'Tone-wase' slices and $\mathrm{C}^{*}$ values on 'Fuyu' slices were lower in enzyme-peeled samples than knife-peeled samples, whereas no differences were found in $\mathrm{C}^{*}$ values on 'Tonewase' slices between the enzyme-peeled and knife-peeled samples (Table 2). Enzymatic peeling decreased the $\mathrm{pH}$ of 'Fuyu' slices but not of 'Tone-wase' slices, and it did not affect the texture of 'Fuyu' and 'Tone-wase' slices. Enzymatically peeled citrus segments have been shown to be visually shinier and firmer than conventionally hand-peeled segments with grapefruit (Rouhana and Mannheim, 1994) and mandarin (Liu et al., 2004). With 'Valencia' and 'Hamlin' oranges, the appearance of enzymepeeled fruit was preferred for 'Hamlin' oranges (Pinnavaia et al., 2007). In this study, enzymepeeled 'Tone-wase' persimmon slices showed a better appearance than 'Fuyu' slices when compared with each knife-peeled slices. Enzyme-peeled 'Fuyu' slices with low L* and
$C^{*}$ values seemed to be visually unmarketable. The difference may be related to the differences in the properties such as morphology and physiological age of the peel and flesh, because 'Fuyu' is a late-maturing cultivar and 'Tonewase' is an early-maturing cultivar.

In conclusion, enzymatic peeling of 'Fuyu' and 'Tone-wase' persimmons resulted in a substantial microbial reduction of fresh-cut slices, and there were no major differences in the physicochemical quality between enzyme-peeled and knife-peeled fresh-cut 'Tone-wase' persimmon slices. Therefore, enzymatic peeling of 'Tone-wase' persimmons would be highly suitable for the freshcut industry in Japan. Although more studies on storage stability of enzyme-peeled 'Tonewase' persimmon slices are necessary to store and transport the products, this new technology is anticipated to increase the production of fresh-cut persimmons and minimize manual labor.

\section{Literature Cited}

Beuchat, L.R. 1996. Pathogenic microorganisms associated with fresh produce. J. Food Prot. 59:204-216.

Bruemmer, J.H., A.W. Griffin, and O. Onayemi. 1978. Sectionizing grapefruit by enzyme digestion. Proc. Fla. State Hort. Soc. 91:112-114.

Emadi, B., M.H. Abbaspour-Fard, and P.K.D.V. Yarlagadda. 2008. Mechanical peeling of pumpkins. Part 1: Using an abrasive-cutter brush. J. Food Eng. 89:448-452.

Fan, X., B.A. Annous, J.C. Beaulieu, and J.E. Sites. 2008. Effect of hot water surface pasteurization of whole fruit on shelf life and quality of freshcut cantaloupe. J. Food Sci. 73:M91-M98.

Garcia, E. and D.M. Barrett. 2006. Peelability and yield of processing tomatoes by steam or lye. J. Food Processing and Preservation. 30:3-14.

Heaton, J.C. and K. Jones. 2008. Microbial contamination of fruit and vegetables and the behaviour of enteropathogens in the phyllosphere: A review. J. Appl. Microbiol. 104:613-626.

Izumi, H. 1999. Electrolyzed water as a disinfectant for fresh-cut vegetables. J. Food Sci. 64:536-539.

Izumi, H., Y. Tsukada, J. Poubol, and K. Hisa. 2008a. On-farm sources of microbial contamination of persimmon fruit in Japan. J. Food Prot. 71:52-59.

Izumi, H., K. Hisa, and Y. Murakami. 2008b. Sanitation and microbiological quality in production field and fruit-packing shed of persimmon and satsuma mandarin in Japan. Microbiol. Insights. 1:25-40.

Liu, F., A. Osman, S. Yusof, and H.M. Ghazali. 2004. Effects of enzyme-aided peeling on the quality of local mandarin (Citrus Reticulata B.) segments. J. Food Processing and Preservation. 28:336-347.

Ozaki, Y., H. Yamanishi, M. Kimura, and M. Nakauchi. 2004. Method for peeling of persimmon fruit and peeled persimmons. JP Patent No. 3617042.

Pao, S., P.D. Petracek, and G.E. Brown. 1996 Effect of infusion method on peel removal and storage quality of citrus. HortTechnology 6:409413.

Pinnavaia, S., E.A. Baldwin, A. Plotto, J. Narciso, and E. Senesi. 2006. Enzyme-peeling of Valencia oranges for fresh-cut slices. Proc. Fla. State Hort. Soc. 119:335-339.

Pinnavaia, S., E. Senesi, A. Plotto, J.A. Narciso, and E.A. Baldwin. 2007. Flavor and other quality factors of enzyme-peeled oranges treated with citric acid. HortScience 42:1644-1650.

Poubol, J. and H. Izumi. 2005. Shelf life and microbial quality of fresh-cut mango cubes stored in high $\mathrm{CO}_{2}$ atmospheres. J. Food Sci. 70:M69-M74.

Prakash, S., R.S. Singhal, and P.R. Kulkarni. 2001. Enzymic peeling of Indian grapefruit (Citrus paradisi). J. Sci. Food Agr. 81:1440-1442.

Pretel, M.T., M.Á. Botella, A. Amorós, M. Serrano, I. Egea, and F. Romojaro. 2007. Obtaining fruit segments from a traditional orange variety [Citrus sinensis (L.) Osbeck cv. Sangrina] by enzymatic peeling. Eur. Food Res. Technol. 225:783-788

Pretel, M.T., P. Lozano, F. Riquelme, and F. Romojaro. 1997. Pectic enzymes in fresh fruit processing: Optimization of enzymic peeling of oranges. Process Biochem. 32:43-49.

Rouhana, A. and C.H. Mannheim. 1994. Optimization of enzymatic peeling of grapefruit. Lebensm.-Wiss. U.-Technol. 27:103-107.

Sakai, T. 1988. Protopectinase from yeasts and a yeastlike fungus. Methods Enzymol. 161:335350 .

Sakho, M., D. Chassagne, A. Jaus, E. Chiarazzo, and J. Crouzet. 1998. Enzymatic maceration: Effects on volatile components of mango pulp. J. Food Sci. 63:975-978.

Soffer, T. and C.H. Mannheim. 1994. Optimization of enzymatic peeling of oranges and pomelo. Lebensm.-Wiss. U.-Technol. 27:245-248.

Solomon, E.B., L. Huang, J.E. Sites, and B.A. Annous. 2006. Thermal inactivation of Salmonella on cantaloupes using hot water. J. Food Sci. 71:M25-M30.

Suutarinen, M., A. Mustranta, K. Autio, M. Salmenkallio-Marttila, R. Ahvenainen, and J. Buchert. 2003. The potential of enzymatic peeling of vegetables. J. Sci. Food Agr. 83: 1556-1564.

Toker, İ. and A. Bayındırl. 2003. Enzymatic peeling of apricots, nectarines and peaches. Lebensm.Wiss. U.-Technol. 36:215-221.

Ukuku, D.O. and G.M. Sapers. 2001. Effect of sanitizer treatments on Salmonella Stanley attached to the surface of cantaloupe and cell transfer to fresh-cut tissues during cutting practices. J. Food Prot. 64:1286-1291. 